\title{
Textile Dye Removal Using Pelletized Agro waste
}

\author{
Lekha K B*, Vasumathi G S, Neelam R K, Archna \\ *Department of Chemical Engineering, M.S. Ramaiah Institute of Technology, M.S.R.I.T Post, Bangalore- \\ 560054, Karnataka, India,
}

\begin{abstract}
Dye removal using low cost adsorbent is a suitable method for textile wastewater treatment. The aim of the present work is application of sawdust, areca nut and guava leaves in powdered and pelletized form using corn starch as a binder as low cost adsorbent for methylene blue removal from textile wastewater at laboratory scale. Batch studies were carried out for the removal of dye methylene blue using powdered and pelletized agro wastes at a neutral pH 7 and other parameters studied included adsorbent dose, initial dye concentration and contact time. The study revealed that powdered and pelletized agro wastes have less adsorption as compared to powdered agro wastes, as cited in literature. It was observed that pelletized sawdust showed $32 \%$ removal for a dosage of $2 \mathrm{gm}$ at a contact time of $120 \mathrm{~min}$ for a dye concentration ranging between 5-25ppm. It was observed that powdered and pelletized areca nut showed 58\% removal for a dosage of 3.2gm at a contact time of $120 \mathrm{~min}$ for a dye concentration ranging between 5-25ppm. It was observed that powdered and pelletized guava leaves showed $90 \%$ removal for a dosage of $2.4 \mathrm{gm}$ at a contact time of $120 \mathrm{~min}$ for a dye concentration ranging between 5-25ppm. It was observed guava leaves pellets were the best adsorbent. Langmuir and Freundlich isotherms were made to determine the constants. Adsorption kinetics were studied.It was found that adsorption followed second order kinetics. The present work will help to carry out studies in packed column and later scale it up for industrial application.
\end{abstract}

\section{Introduction}

Water pollution caused by dyes has been of great concern since the dyes cause significant environmental problems. The presence of dyes in water leads to depletion of dissolved oxygen effecting the aquatic environment. Usage of the dyes increases the turbidity of water body which in turn hampers the photosynthesis process causing alteration in the habitat. The major sources of environmental pollution with dye are textile, leather, paper, food and wood industries (Namasivayam et.al., 1994).

Methylene blue is one of the widely used dyes in the industries and also in the medical and biological field. Industries produce large amount of wastewater mainly charged with unconsumed methylene blue leading to the contamination of water. The objective of present work was to study the removal of methylene blue dye using pelletized agro wastes.

\section{Literature Review}

Due to the commercial importance of dyes, their impact (Khattri et.al., 1999) and toxicity when released in the environment have been extensively studied and many methods have been introduced for their removal. Hence the recent studies mainly concentrate on the other alternatives which are more eco-friendly and can overcome the problems faced in using conventional techniques. Biosorption is a convenient alternative method. This process involves a solid phase (sorbent or biosorbent; adsorbent; biological material) and a liquid phase (solvent, normally water) (Mane et.al., 2012) containing a dissolved species to be sorbed (adsorbate, metal).Biosorption has got many advantages such as less cost, no production of chemical sludge, easy operation and more efficiency. The technologies for color removal can be divided into three categories: biological, chemical and physical. All of them have advantages and drawbacks.

Biological methods: Biodegradation methods such as fungal decolorization, microbial degradation, adsorption by (living or dead) microbial biomass and bioremediation systems are commonly applied to the treatment of industrial effluents because many microorganisms such as bacteria, yeasts, algaes and fungi are able to accumulate and degrade different pollutants. However, their application is often restricted because of technical constraint. Biological treatment requires a large land area and is constrained by sensitivity toward diurnal variation as well as toxicity of some chemicals, and less flexibility in design and operation (Somasekhara et.al, 2006).

Chemical methods: Chemical methods include coagulation or flocculation combined with flotation and filtration, precipitation-flocculation with $\mathrm{Fe}(\mathrm{II}) / \mathrm{Ca}(\mathrm{OH})_{2}$, electroflotation, electrokinetic coagulation, conventional oxidation methods by oxidizing agents (ozone), irradiation or electrochemical processes. These chemical techniques are often expensive, and although the dyes are removed, accumulation of concentrated sludge creates a disposal problem. 
Physical methods: Different physical methods are also widely used, such as membrane - filtration processes (nanofiltration, reverse osmosis, electro dialysis) and adsorption techniques. The major disadvantages of the membrane processes is that they have a limited lifetime before membrane fouling occurs and the cost of periodic replacement must thus be included in any analysis of their economic viability. In accordance with the very abundant literature data, liquid-phase adsorption is one of the most popular methods for the removal of pollutants from wastewater.

Adsorption is a process that occurs when a gas or liquid solute accumulates on the surface of a solid or a liquid (adsorbent), forming a molecular or atomic film (the adsorbate). It is different from absorption, in which a substance diffuses into a liquid or solid to form a solution (Mohan et.al., 2002). Adsorption is operative in most natural physical, biological, and chemical systems, and is widely used in industrial applications such as activated charcoal, synthetic resins and water purification.

\section{Materials And Methods}

Selection and preparation of adsorbent: Low cost adsorbents such as rice husk, cotton, apple pomades, wheat straw, banana and orange peel, guava leaf which are available abundantly and eco-friendly have been used extensively for biosorption of various pollutants. Agro wastes such as areca nut, teak wood saw dust and guava leaves (Ponnusami et.al., 2008) were collected and washed with distilled water and sun dried so that they do not contain any moisture. After drying process, agro wastes were ground to fine powder and sieved through -44 mesh $(176.5 \mu \mathrm{m})$. Agro waste pellets were prepared by mixing corn starch binder and agro waste powder. The pellets were $14 \mathrm{~mm}$ in diameter and $5 \mathrm{~mm}$ in thickness. These pellets were kept in hot air oven for drying at the temperature of $77^{\circ} \mathrm{C}$. Proximate analysis was carried out to estimate moisture content, volatile content and ash content of pelletized biosorbents using muffle furnace. The results are presented in Table1.

Table 1: Properties of pelletized biosorbents

\begin{tabular}{|l|l|l|l|}
\hline \multirow{2}{*}{ Parameter } & \multicolumn{2}{|c|}{ Value } & Guava leaf \\
\cline { 2 - 4 } & Sawdust & Areca nut & 0.381 \\
\hline Moisture content $(\mathrm{gm})$ & 0.561 & 0.279 & 3.812 \\
\hline Volatile content $(\mathrm{gm})$ & 3.983 & 0.2 & 0.847 \\
\hline Ash content $(\mathrm{gm})$ & 0.382 & 4.528 & 176.5 \\
\hline Particle size $(\mu \mathrm{m})$ & 176.5 & 176.5 & \\
\hline
\end{tabular}

Batch Experiments: 5,10,15,20 and 25 ppm of methylene blue dye solutions were prepared. $75 \mathrm{ml}$ of dye solution was taken in a conical flask for batch adsorption study.

- Effect of agitation time: 0.5 grams of saw dust, $0.8 \mathrm{~g}$ of areca nut and $0.6 \mathrm{~g}$ of guava leaves pellets were used. The flasks were kept on mechanical shaker and concentration of dye was measured at different time intervals using a UV - Vis spectrophotometer.

- Effect of adsorbent dosage: The amount of adsorbent used for saw dust,viz., 0.5, 1, 1.5 and $2 \mathrm{~g}$, for areca nut ,viz.,0.8, 1.6, 2.4 and $3.2 \mathrm{~g}$ and for guava leaves ,viz.,0.6, 1.2, 1.8 and 2.4.The flasks were kept in mechanical shaker for 120 minutes (optimum time) and then analyzed using UV - Vis spectrophotometer. These experiments were carried out at neutral $\mathrm{pH}$.

Adsorption isotherm models: The Langmuir adsorption model was chosen for estimation of maximum dye sorption by the adsorbent, which is represented as (Suteu et.al., 2011)

$\mathrm{Q}=\mathrm{Q}_{\max } \mathrm{b} \mathrm{C}_{\mathrm{f}} / 1+\mathrm{bC}_{\mathrm{f}}$ where $\mathrm{Q}_{\max }$ indicates the monolayer adsorption capacity of adsorbent $(\mathrm{mg} / \mathrm{g})$ and the Langmuir constant $\mathrm{b}(\mathrm{L} / \mathrm{mg})$ is related to the energy of adsorption. For fitting the experimental data, the Langmuir model was linearized as

$1 / \mathrm{Q}=1 / \mathrm{Q}_{\max }+1 / \mathrm{bQ}_{\max } \mathrm{C}_{\mathrm{f}}$

The other model was Freundlich model which is represented by the equation,

$\mathrm{Q}=\mathrm{K}\left(\mathrm{C}_{\mathrm{f}}\right) 1 / \mathrm{n}$ where $\mathrm{K}(\mathrm{mg} / \mathrm{g})$ is the Freundlich constant related to adsorption capacity of adsorbent and $\mathrm{n}$ is the Freundlich exponent related to adsorption intensity (dimensionless). For fitting the experimental data the Freundlich model was linearized as follows,

$\ln Q=\ln K+1 / n \ln C_{f}$

Adsorption kinetics The kinetics studies were carried out by conducting batch adsorption experiments with different initial dye concentrations. Samples were taken at different time periods and analyzed for dye concentration.

\section{Results And Discussions}

Effect of agitation time: The effect of agitation time for methylene blue adsorption was studied for various concentrations of dye. The $\mathrm{pH}$ was maintained at 7 and adsorbent dosage was kept constant. The concentration of dye decreased with the increase in time and after 120 minutes the concentration was constant (Figure 1, 2 $\& 3)$.It can be concluded that 120 minutes was the optimum time for adsorption. 


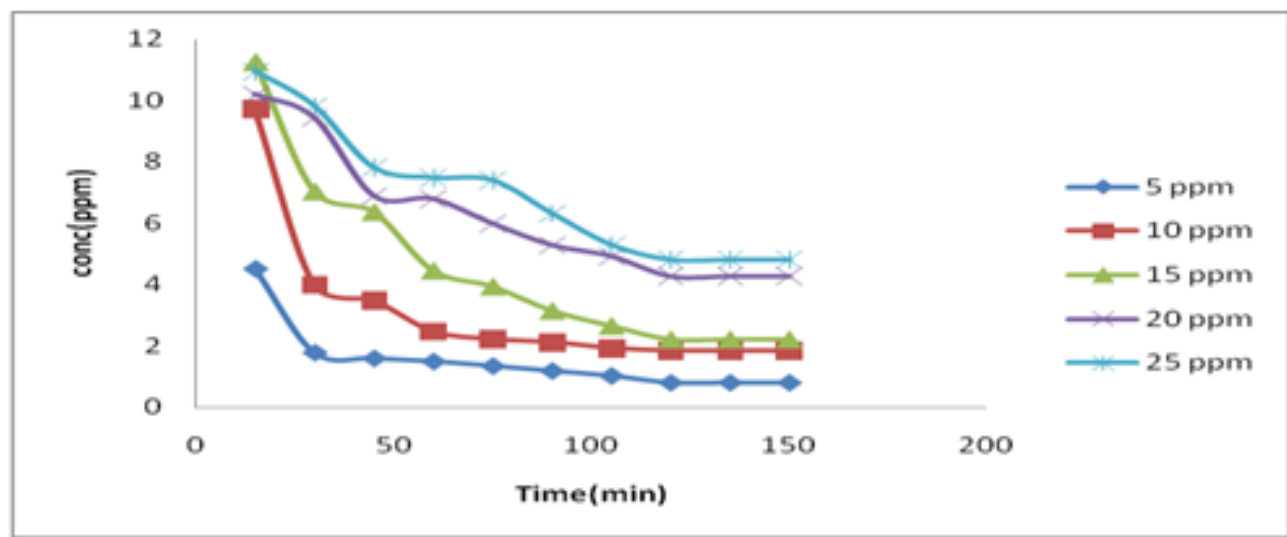

Figure 1: Effect of contact time on different initial concentrations of methylene blue at $\mathrm{pH} 7$ and saw dust pellets dosage of $0.5 \mathrm{~g}$.

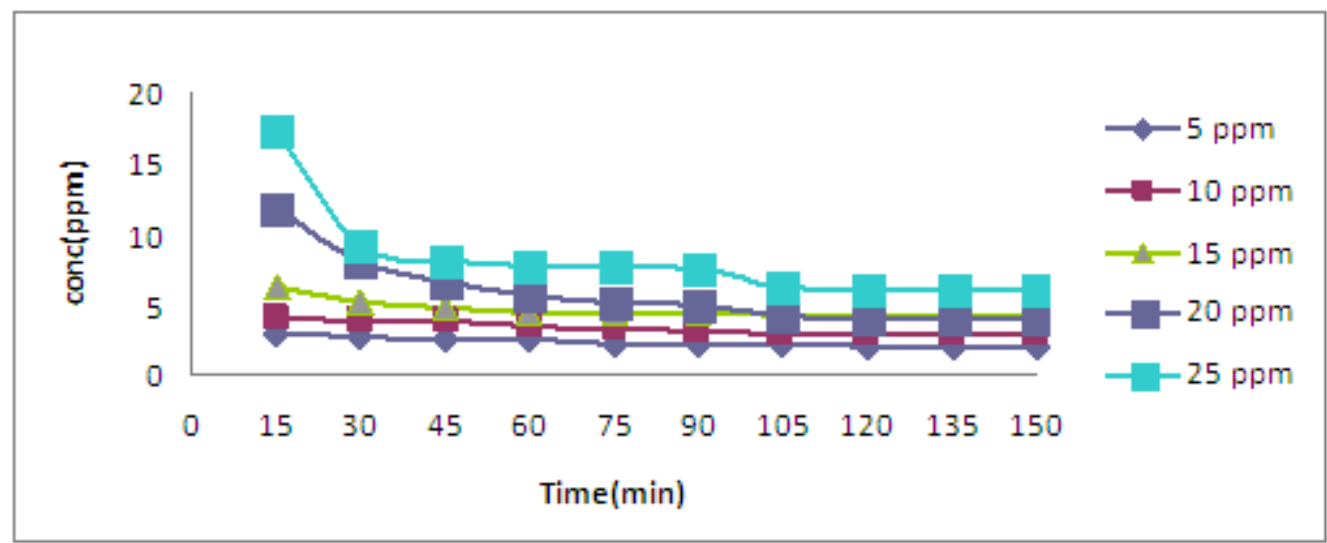

Figure 2: Effect of contact time on different initial concentrations of methylene blue at $\mathrm{pH} 7$ and areca nut pellets dosage of $0.8 \mathrm{~g}$

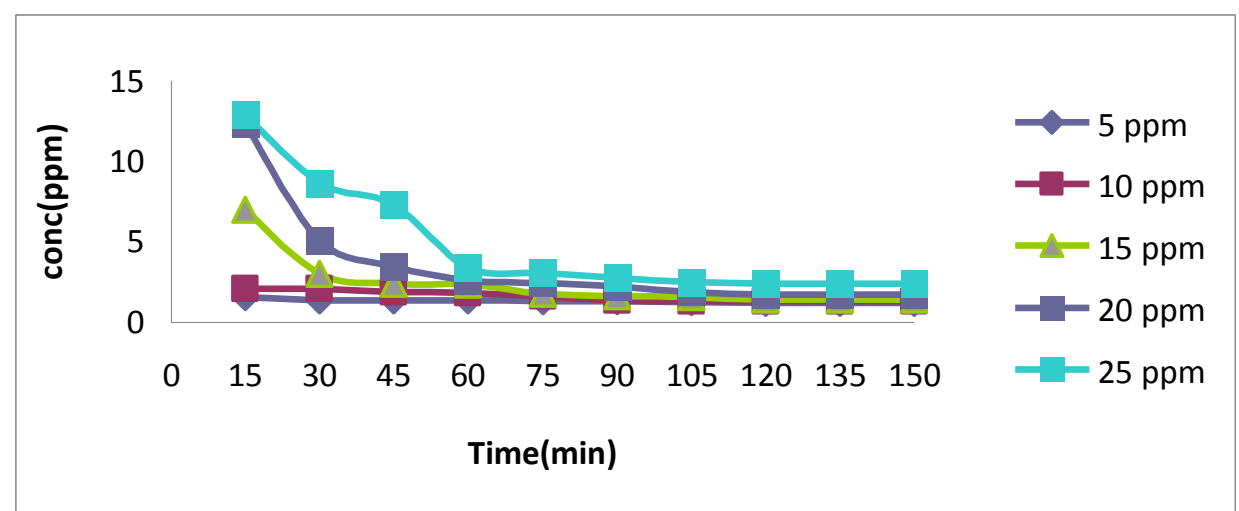

Figure 3: Effect of contact time on different initial concentrations of methylene blue at $\mathrm{pH} 7$ and guava leaves pellets dosage of $0.6 \mathrm{~g}$

\section{Effect of adsorbent dosage:}

The amount of adsorbents added was varied from 0- 3 grams for each batch experiment at optimum time and neutral $\mathrm{pH}$. The variation of dye concentration with adsorbent dosage is shown in Figure 4, 5, 6. It is seen that after 2 grams of saw dust pellets addition no change in concentration takes place for dye. 


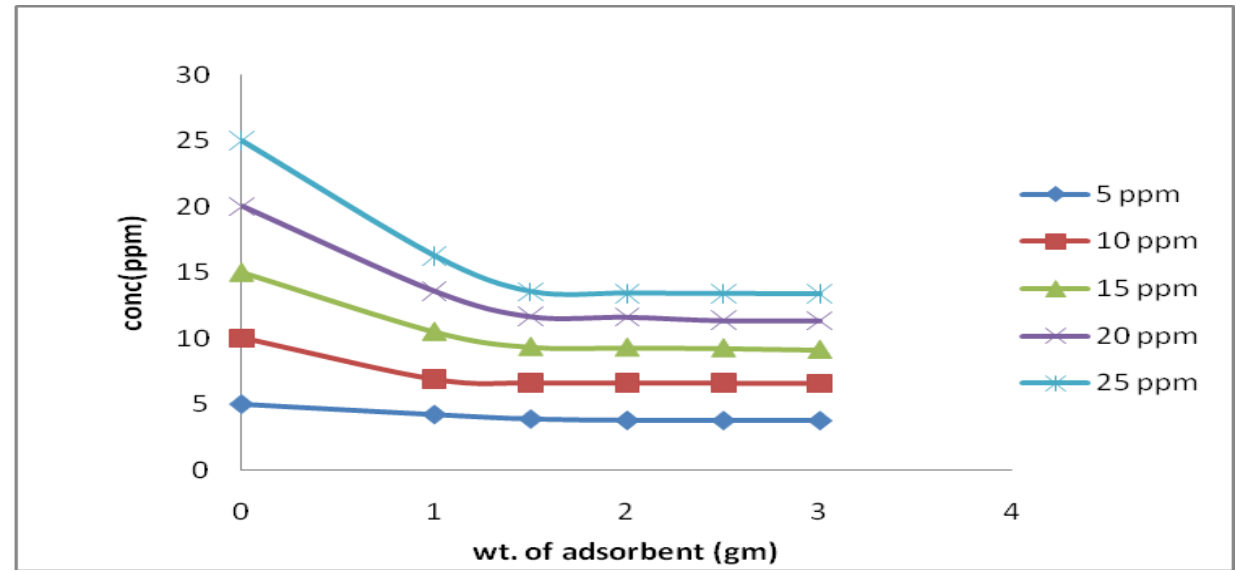

Figure.4: Effect of weight of sawdust pellets for different initial concentrations of methylene blue at $\mathrm{pH} 7$ and optimum time of 120 minute

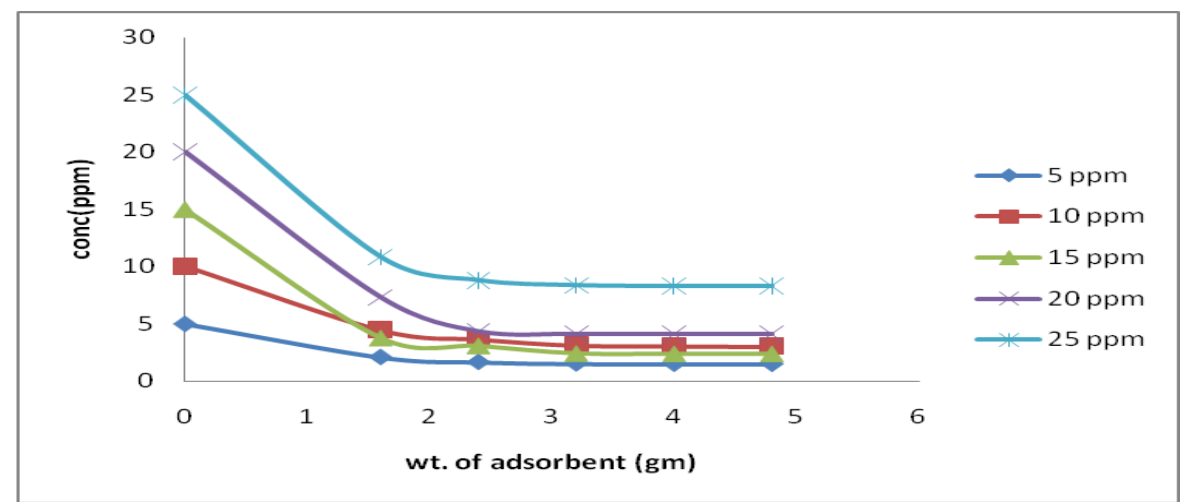

Figure 5: Effect of weight of areca nut pellets for different initial concentrations of methylene blue at $\mathrm{pH} 7$ and optimum time of 120 minute

From the Figure 5 it was seen that $3.2 \mathrm{~g}$ of areca nut pellets is optimum dosage for removal.

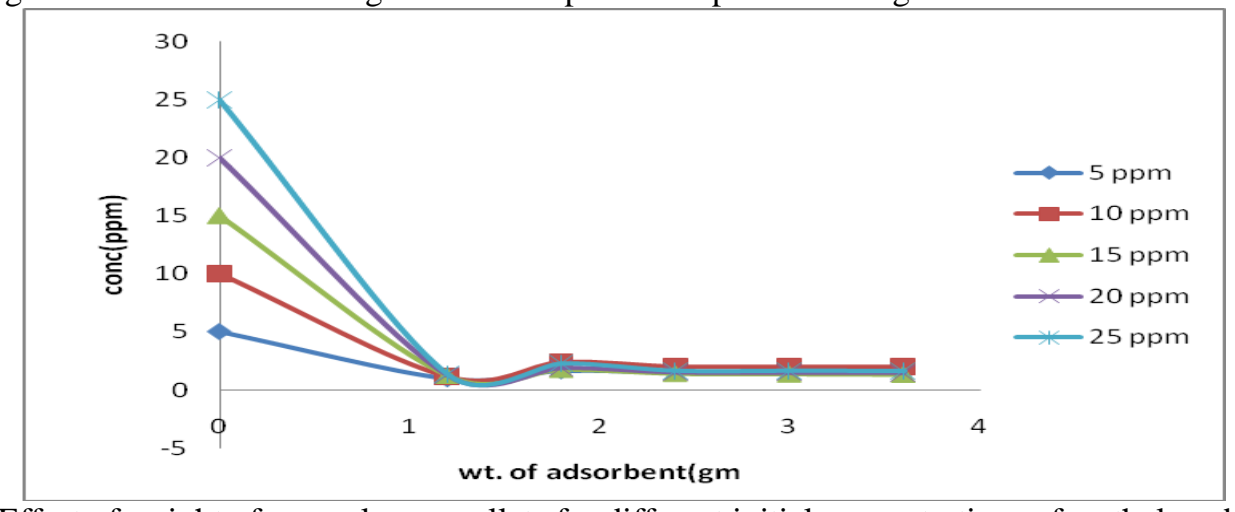

Figure 6: Effect of weight of guava leaves pellets for different initial concentrations of methylene blue at $\mathrm{pH} 7$ and optimum time of 120 minute

From the Figure 6 it was seen that $2.4 \mathrm{~g}$ of guava leaves pellets is the optimum dosage.

Batch adsorption isotherms: The data obtained from batch studies was used to fit Langmuir and Freundlich isotherm models.

- Langmuir isotherm:A plot of $\mathrm{C}_{\mathrm{e}} / \mathrm{q}_{\mathrm{e}}$ versus $\mathrm{C}_{\mathrm{e}}$ was made which indicated homogeneous adsorption distribution of Langmuir isotherm. The values of constant $\mathrm{b}$ and $\mathrm{Q}_{\mathrm{m}}$ were obtained from the intercept and the slope of graph, (Figure 7, 8, 9). 


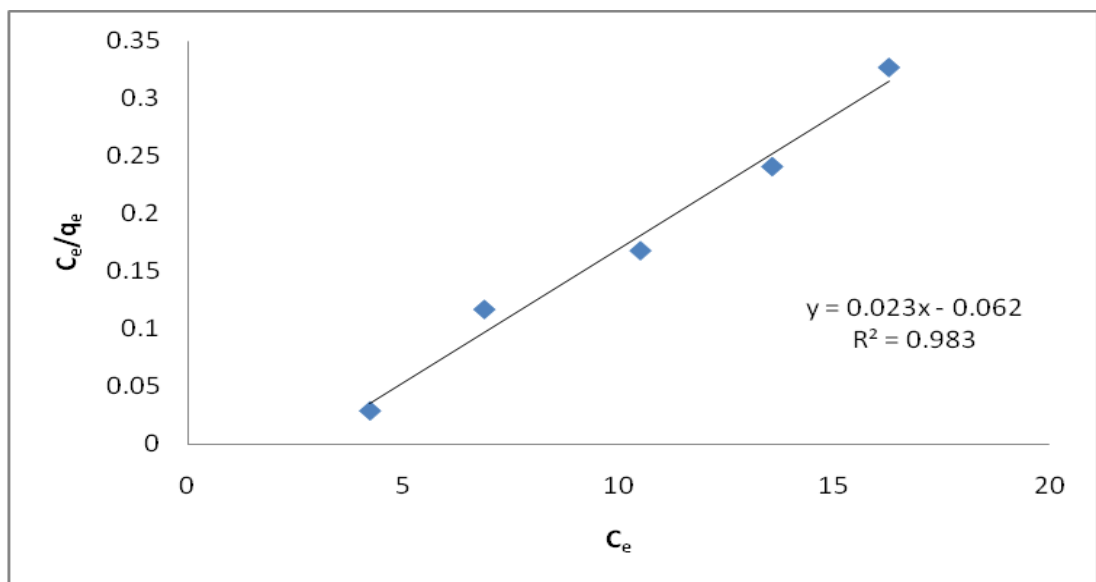

Figure 7: Langmuir isotherm for sawdust at optimum conditions

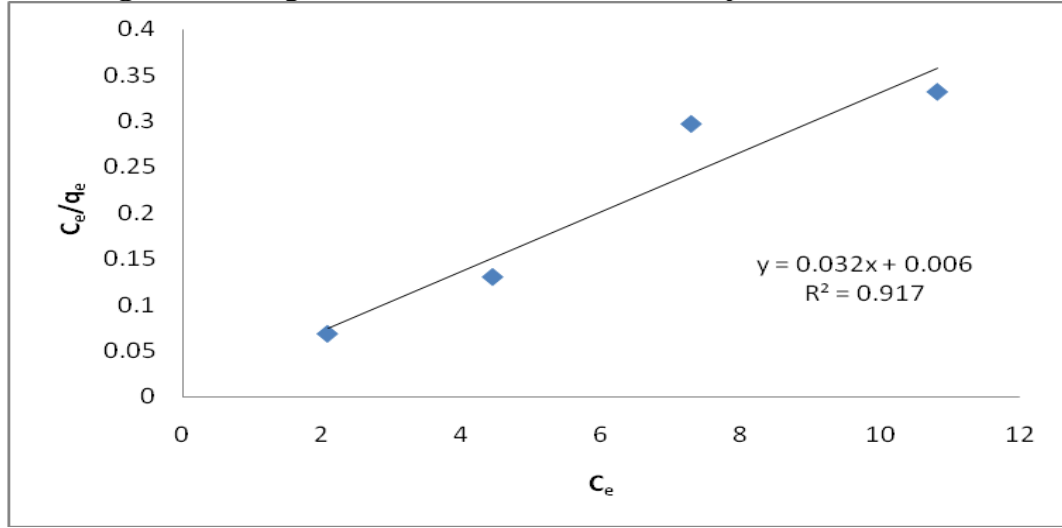

Figure 8: Langmuir isotherm for areca nut at optimum conditions

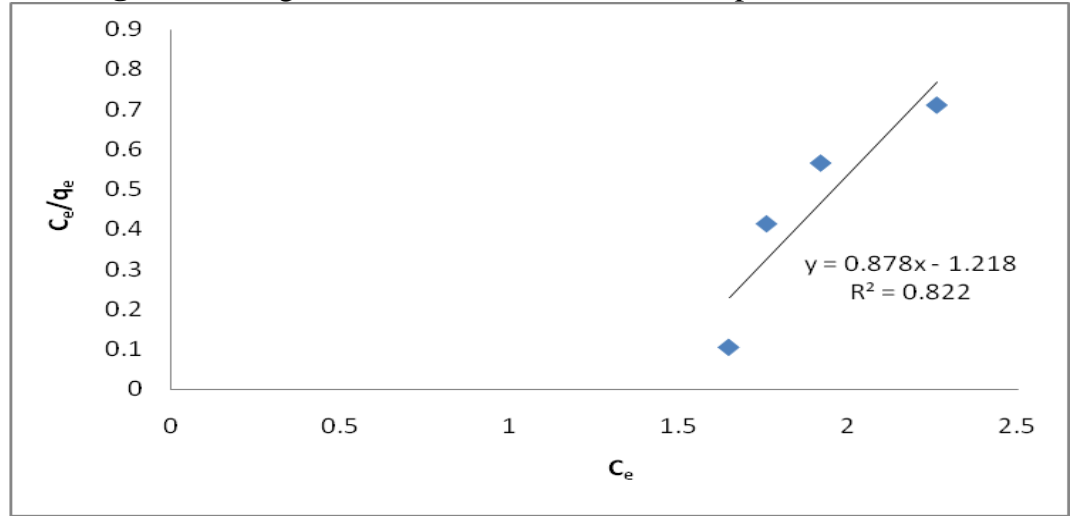

Figure 9: Langmuir isotherm for guava leaves at optimum conditions

- Freundlich isotherm: A graph of $\log \mathrm{q}_{\mathrm{e}} \mathrm{vs} \log \mathrm{C}_{\mathrm{e}}$ was plotted based on the data obtained from experiments. The constants $\mathrm{k}_{\mathrm{f}}$ and $\mathrm{n}$ were obtained (Figure 10, 11, 12).

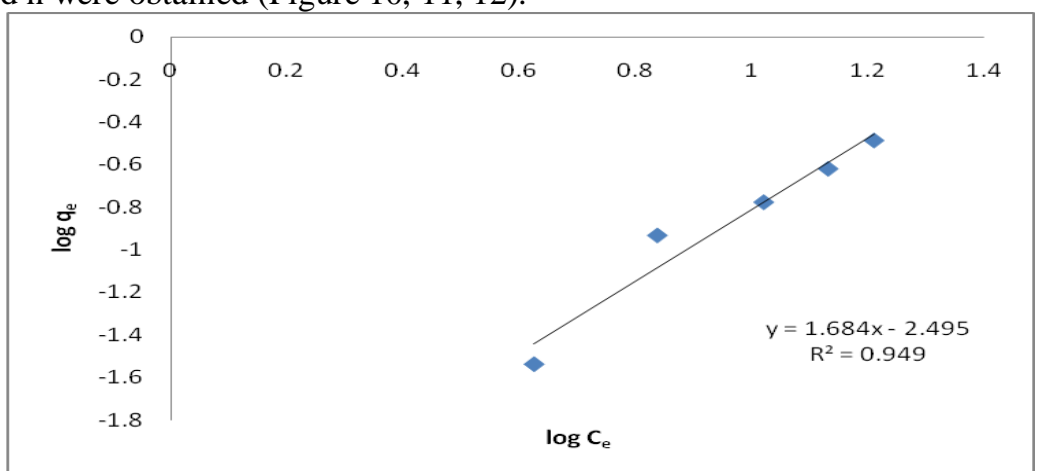

Figure 10: Freundlich isotherm for sawdust at optimum conditions 


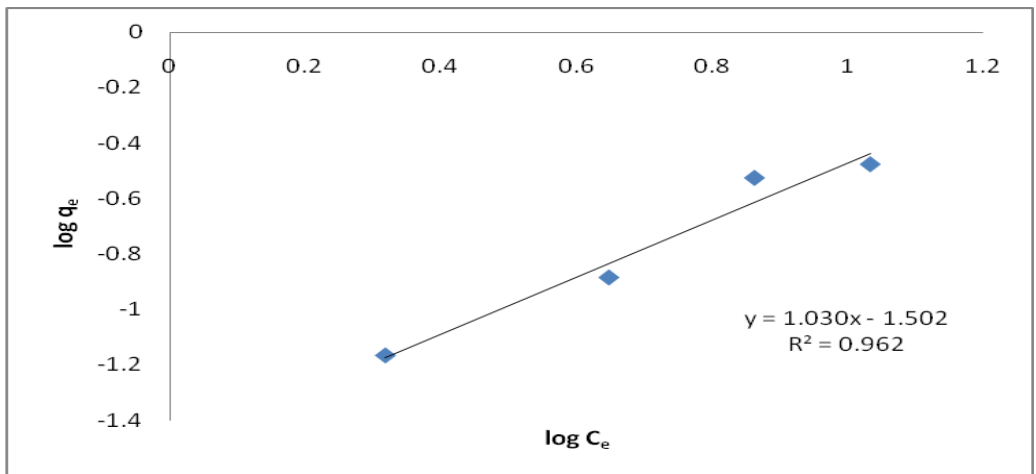

Figure 11: Freundlich isotherm for areca nut at optimum conditions

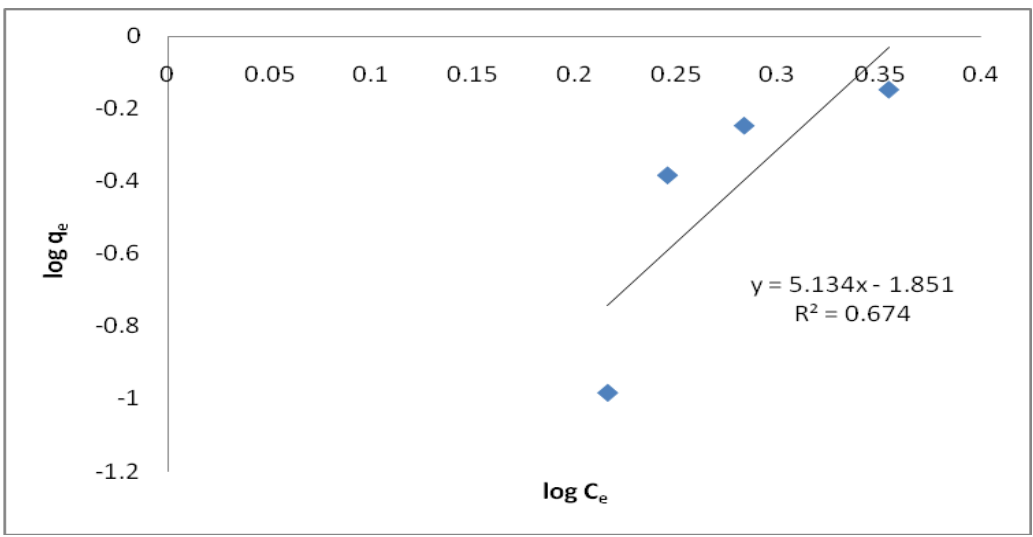

Figure 12: Freundlich isotherm for guava leaves at optimum conditions

The Langmuir and Freundlich isotherm constants for all the adsorbents under optimum conditions for the removal of Methylene blue dye are shown in Table 2.

Table 2: Constants for various Biosorbents using different Adsorption Models

\begin{tabular}{|l|l|l|l|l|l|l|}
\hline \multirow{2}{*}{ Adsorbents } & \multicolumn{4}{|l|}{ Langmuir Isotherm } & \multicolumn{2}{l|}{ Freundlich Isotherm } \\
\cline { 2 - 7 } & $\mathbf{Q}_{\mathbf{m}}$ & $\mathbf{R}^{\mathbf{2}}$ & $\mathbf{b}$ & $\mathbf{k}_{\mathbf{F}}$ & $\mathbf{n}$ & $\mathbf{R}^{\mathbf{2}}$ \\
\hline Sawdust & 43.478 & 0.983 & -0.370 & 0.00319 & 0.593 & 0.949 \\
\hline Areca nut & 31.25 & 0.917 & 5.333 & 0.0314 & 0.97 & 0.962 \\
\hline Guava Leaves & 1.1381 & 0.822 & -0.720 & 0.014 & 0.194 & 0.674 \\
\hline
\end{tabular}

\section{Adsorption kinetics:}

The prediction of adsorption rate gives important information for designing batch adsorption systems. Information on the kinetics of solute uptake is required for selecting optimum operating conditions for full scale batch process. The adsorption rate for first 30 mins was observed to be very high and thereafter the reaction proceeded at a slower rate till equilibrium and finally a steady state was obtained. The saturation time was found to be 120 mins based on initial dye concentration. The kinetics of the adsorption data was analyzed using two kinetic models, pseudo-first order and pseudo-second order kinetic model. These models help to correlate solute uptake, which are important in predicting the reactor volume. The pseudo first order equation is given as

$$
\mathrm{dq}_{\mathrm{t}} / \mathrm{dt}=\mathrm{k}_{1}\left(\mathrm{q}_{\mathrm{e}}-\mathrm{q}_{\mathrm{t}}\right)
$$

After integration and linearization,

$$
\ln \left(\mathrm{q}_{\mathrm{e}}-\mathrm{q}_{\mathrm{t}}\right)=\ln \mathrm{q}_{\mathrm{e}}-\mathrm{k}_{1} \mathrm{t}
$$

Where $\mathrm{q}_{\mathrm{e}}=$ the amount of methylene blue adsorbed at equilibrium $(\mathrm{mg} / \mathrm{g})$

$\mathrm{q}_{\mathrm{t}}=$ the amount of methylene blue adsorbed at time $\mathrm{t}(\mathrm{mg} / \mathrm{g}) \mathrm{k}_{1}=$ the rate constant of the adsorption process (min-1)

The pseudo second order kinetic equation used to analyze adsorption data for different adsorbates and adsorbents is given as

$\mathrm{dq}_{\mathrm{t}} / \mathrm{dt}=\mathrm{k}_{2}\left(\mathrm{q}_{\mathrm{e}}-\mathrm{qt}\right)^{2}$

After integration and linearization,

$\mathrm{t} / \mathrm{q}_{\mathrm{t}}=1 / \mathrm{k}_{2} \mathrm{q}_{\mathrm{e}}^{2}+\mathrm{t} / \mathrm{q}_{\mathrm{e}}$

Where, $\mathrm{k}_{2}=$ constant, $\mathrm{q}_{\mathrm{t}}=$ amount of dye adsorbed per unit weight of adsorbent $(\mathrm{g})$ at time $\mathrm{t} \mathrm{q}_{\mathrm{e}}=$ amount of dye adsorbed per unit weight of adsorbent. 
The experimental data showed that adsorption by all the used biosorbents did not follow pseudo-first order kinetics. For pseudo-second order kinetics the plots of $t / \mathrm{q}_{\mathrm{t}} \mathrm{Vs} t$ for different biosorbents at different concentrations were made.

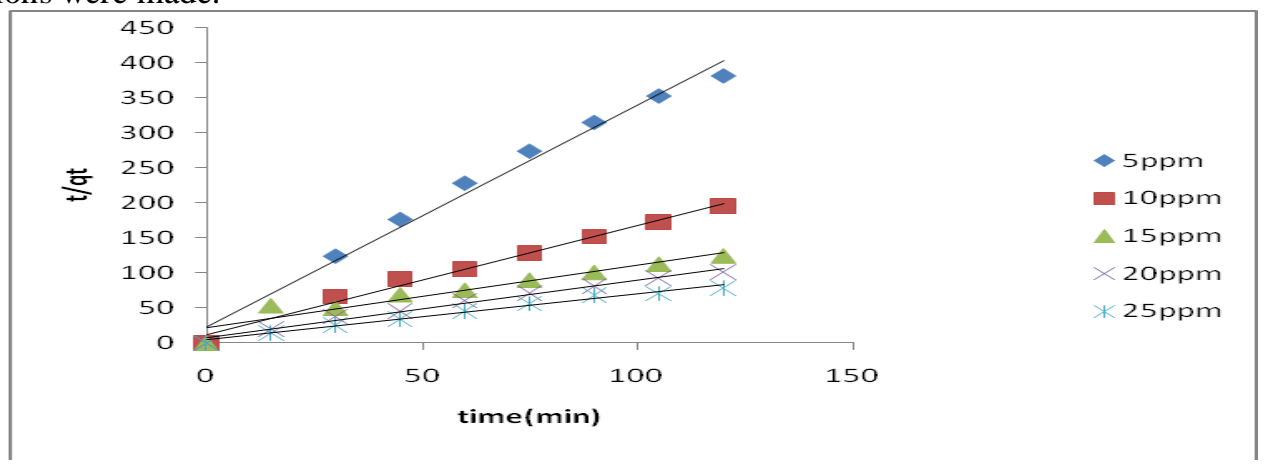

Figure 13: Pseudo second order reaction model at optimum conditions of adsorbent saw dust for different initial methylene blue concentration.

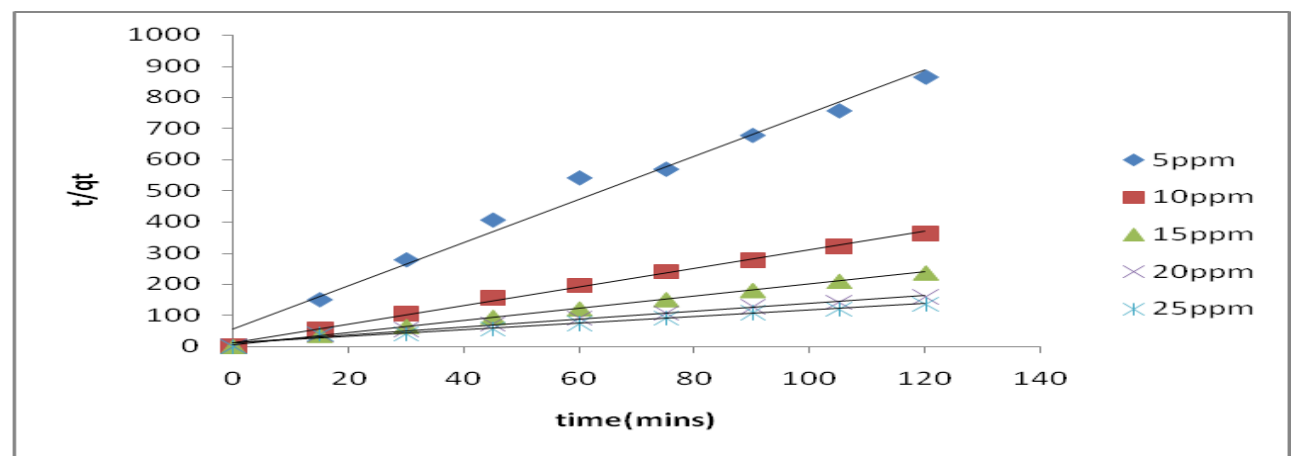

Figure 14: Pseudo second order reaction model at optimum conditions of adsorbent areca nut for different initial methylene blue concentration.

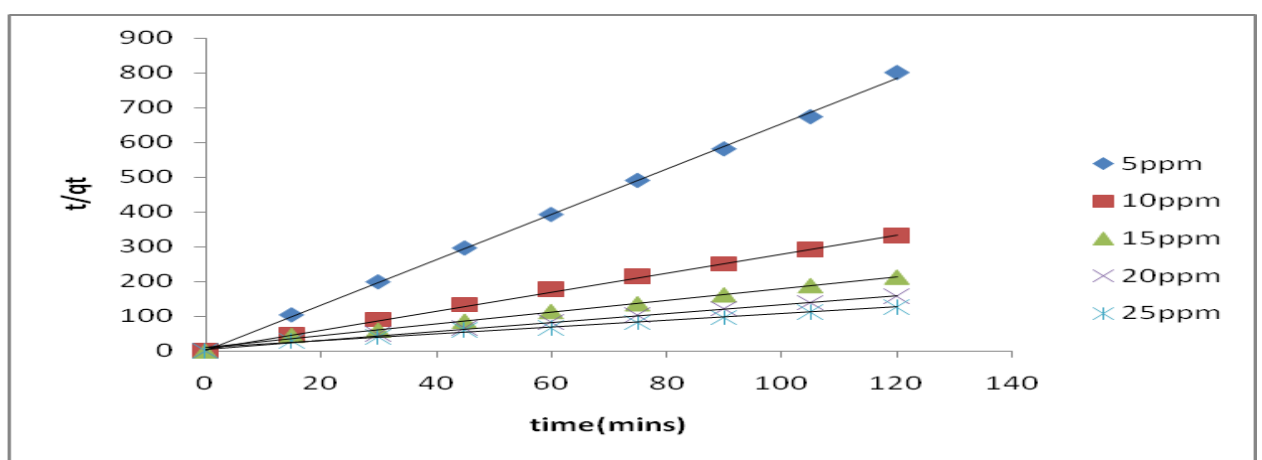

Figure 15: Pseudo second order reaction model at optimum conditions of adsorbent guava leaves for different initial methylene blue concentration.

Figure 13, 14, 15 shows a linear variation with time having a positive slope. Table 3 gives Pseudo second- order kinetic model constants for various adsorbents. The data obtained for adsorption kinetics follows second order for the adsorption of methylene blue at optimum conditions.

Table 3: Second-order kinetic constants for various Biosorbents

\begin{tabular}{|c|c|c|c|c|c|c|c|c|c|}
\hline \multirow{2}{*}{$\begin{array}{l}\text { Initial } \\
\text { concentration } \\
(\mathrm{ppm})\end{array}$} & \multicolumn{3}{|c|}{ Sawdust } & \multicolumn{3}{|c|}{ Areca nut } & \multicolumn{3}{|c|}{ Guava leaves } \\
\hline & $\mathbf{k}_{2}$ & $q_{e, c a l}(m g / g)$ & $\mathbf{R}^{2}$ & $\mathbf{k}_{2}$ & $q_{e, c a l}(m g / g)$ & $\mathbf{R}^{2}$ & $\mathbf{k}_{2}$ & $q_{e, c a l}(m g / g)$ & $\mathbf{R}^{2}$ \\
\hline 5 & 0.4189 & 0.3163 & 0.985 & 0.88 & 0.143 & 0.996 & 24.73 & 0.153 & 0.999 \\
\hline 15 & 0.0359 & 1.123 & 0.9221 & 0.838 & 0.512 & 0.999 & 0.309 & 0.587 & 0.994 \\
\hline 20 & 0.0862 & 1.212 & 0.9858 & 0.317 & 0.776 & 0.996 & 0.317 & 0.776 & 0.996 \\
\hline 25 & 0.0965 & 1.513 & 0.98 & 0.106 & 1.000 & 0.986 & 0.106 & 1.009 & 0.986 \\
\hline
\end{tabular}




\section{Conclusions}

The present study shows that all the three pelletized biosorbents were effective for the removal of methylene blue dye. The adsorption capacity of guava leaves pellets was superior due to the presence of various surface functional groups. The effect of process parameters, viz, initial dye concentration, adsorbent dosage and time of contact were studied. The uptake of methylene blue dye was increased by increasing the time of contact and the adsorbent dosage. The uptake was studied at the $\mathrm{pH}$ of 7.The adsorption isotherms could be well fitted by the Freundlich equation followed by Langmuir equation. The biosorption process could be best described by Pseudo second- order kinetic model.

\section{References}

[1]. Khattri, S.D., Singh, M.K., (1999), Colour removal from dye wastewater using sugar cane dust as an adsorbent, Adsorp. Sci. Technol, 17, 269-282.

[2]. Mane R S, Bhusari V N, (2012), Removal of Color (dyes) from textile effluent by adsorption using Orange and Banana peel, International Journal of Engineering Research and Applications, 2(3), 1997-2004.

[3]. Mohan, D., Singh, K.P., Singh, G., Kumar, K.,( 2002), Removal of dyes from wastewater using fly ash, a low-cost adsorbent, Ind. Eng.Chem., 41, 3688-3695.

[4]. Namasivayam, C., Kadirvelu, K., (1994), Coir pith, an agricultural waste by-product for the treatment of dyeing wastewater, Bioresour. Technol., 38, 79-81.

[5]. Ponnusami V, Srivastava S.N, Vikram S ,(2008), Guava (Psidium guava) leaf powder: Novel adsorbent for removal of methylene blue from aqueous solutions, Journal of Hazardous Materials 152(1), 276-286.

[6]. Somasekhara Reddy M C, (2006), Removal of direct dye from aqueous solutions with an adsorbent made from tamarind fruit shell, an agricultural solid waste, journal of scientific \& industrial research, 65, 443-446.

[7]. Suteu D and Zaharia C (2011), Sawdust as Biosorbent for Removal of Dyes from Wastewaters. Kinetic and Thermodynamic Study, Chemical Bulletin of Politehnica University of Timisoara, ROMANIA Series of Chemistry and Environmental Engineering, 56(70), $85-88$. 